OPEN ACCESS

Edited by:

Kian Mau Goh,

University of Technology Malaysia,

Malaysia

Reviewed by:

Renaud Berlemont,

California State University, Long

Beach, United States

Roberta Verciano Pereira

University of São Paulo, Brazi

*Correspondence:

Jan Dirk van Elsas

j.d.van.elsas@rug.n

tThese authors share first authorship

¥Present address:

Larisa Cortes-Tolalpa,

Agilent Technologies, Amstelveen,

Netherlands

Specialty section: This article was submitted to

Microbiotechnology,

a section of the journa

Frontiers in Microbiology

Received: 10 November 2019

Accepted: 03 February 2020

Published: 03 March 2020

Citation:

Cortes-Tolalpa L, Wang Y,

Salles JF and van Elsas JD (2020)

Comparative Genome Analysis of the

Lignocellulose Degrading Bacteria

Citrobacter freundii so4

and Sphingobacterium multivorum

w15. Front. Microbiol. 11:248.

doi: 10.3389/fmicb.2020.00248

\section{Comparative Genome Analysis of the Lignocellulose Degrading Bacteria Citrobacter freundii so4 and Sphingobacterium multivorum w15}

\author{
Larisa Cortes-Tolalpa ${ }^{\ddagger \neq}$, Yanfang Wang ${ }^{\dagger}$, Joana Falcao Salles and Jan Dirk van Elsas* \\ Cluster of Microbial Ecology, Groningen Institute for Evolutionary Life Sciences, University of Groningen, Groningen, \\ Netherlands
}

Two bacterial strains, denoted so4 and w15, isolated from wheat straw (WS)-degrading microbial consortia, were found to grow synergistically in media containing WS as the single carbon and energy source. They were identified as Citrobacter freundii so4 and Sphingobacterium multivorum w15 based on 16S rRNA gene sequencing and comparison to the respective $C$. freundii and S. multivorum type strains. In order to identify the mechanisms driving the synergistic interactions, we analyzed the draft genomes of the two strains and further characterized their metabolic potential. The latter analyses revealed that the strains had largely complementary substrate utilization patterns, with only 22 out of 190 compounds shared. The analyses further indicated $C$. freundii so4 to primarily consume amino acids and simple sugars, with laminarin as a key exception. In contrast, S. multivorum w15 showed ample capacity to transform complex polysaccharides, including intermediates of starch degradation. Sequence analyses revealed C. freundii so4 to have a genome of 4,883,214 bp, with a $\mathrm{G}+\mathrm{C}$ content of 52.5\%, 4,554 protein-encoding genes and 86 RNA genes. S. multivorum w15 has a genome of $6,678,278$ bp, with a $G+C$ content of $39.7 \%$, 5,999 protein-encoding genes and 76 RNA genes. Genes for motility apparatuses (flagella, chemotaxis) were present in the genome of $C$. freundii so4, but absent from that of S. multivorum w15. In the genome of S. multivorum w15, 348 genes had regions matching CAZy family enzymes and/or carbohydrate-binding modules (CBMs), with 193 glycosyl hydrolase (GH) and 50 CBM domains. Remarkably, 22 domains matched enzymes of glycoside hydrolase family $\mathrm{GH} 43$, suggesting a strong investment in the degradation of arabinoxylan. In contrast, 130 CAZy family genes were found in C. freundii so4, with $61 \mathrm{GH}$ and $12 \mathrm{CBM}$ domains identified. Collectively, our results, based on both metabolic potential and genome analyses, revealed the two strains to harbor complementary catabolic armories, with S. multivorum w15 primarily attacking the WS hemicellulose and C. freundii so4 the cellobiose derived from cellulose, next to emerging oligo- or monosaccharides. Finally, $C$. freundii so4 may secrete secondary metabolites that $S$. multivorum w15 can consume, and detoxify the system by reducing the levels of (toxic) by-products.

Keywords: comparative analysis, synergism, lignocellulose, degradation, bacteria 


\section{INTRODUCTION}

Agricultural waste, such as wheat straw (WS), maize straw and sugar cane bagasse constitutes lignocellulosic biomass (LCB), which is composed of three main components: cellulose, hemicellulose and lignin. The proportion of these components is dependent on the plant species, as well as on the time and conditions of growth (Sorek et al., 2014). LCB substrates represent promising alternatives to carbon sources for the production of useful compounds such as plastics or biodiesel (Guerriero et al., 2016). The utilization of LCB is particularly relevant as mankind is threatened by the depletion of sources of energy as well as global warming (Kumar et al., 2015).

The degradation of LCB not only requires a large variety of hydrolytic enzymes, i.e., cellulases, hemicellulases, and ligninases (Himmel et al., 2007), but also, from each of these three enzymes groups, different types of enzymes with different cleavage specificities. For complete degradation, the (additional) action of carbohydrate-binding modules (CBMs), which bind cellulose or hemicelluloses, and helper enzymes such as lytic polysaccharide monooxygenases (LPMOs), xylan esterases (CEs), and polysaccharide lyases (PLs) are necessary (Koeck et al., 2014).

Degradation of LCB is a complex process. In nature, it is only efficient if diverse microorganisms, mainly bacteria and fungi, contribute (Cragg et al., 2015). These organisms produce diverse lytic as well as auxiliary enzymes, which work in a synergistic manner (Lynd et al., 2002). Moreover, depending on the type of substrate, interactions within the degrader microbial communities emerge, which could be either positive or negative.

"Division of labor" (DOL) is one of the strategies used by microorganisms for dealing with complex substrates (Jiménez et al., 2017). DOL is observed - for example - in a microbial food chain when it is necessary to degrade complex organic compounds. There are examples in the cycles of carbon, as well as of sulfur and nitrogen (Falkowski et al., 2008). According to West and Cooper (2016), DOL can be defined as the cooperation between individuals that are each specialized in specific tasks. Some of the requirements for DOL are (1) presence of diverse phenotypes (individuals that perform different tasks), (2) cooperation, in which the tasks performed by one individual will benefit the other individual, and (3) division of tasks favoring adaptation to the environment (increasing the fitness of the individuals involved). The finding of growth synergy was in line with data by Deng and Wang, in which the presence of a complex source of carbon and energy stimulates synergistic interactions and reduces antagonistic ones (Deng and Wang, 2016). Although it is likely that DOL plays an important role during the degradation of LCB by microbial communities, it remains unclear how and to which extent such interactions take place during the degradation process. Clearly, a better understanding of the process will improve the design and utilization of microbial consortia at industrial level (Song et al., 2014).

In a quest to unravel the degradation of LCB by microbial communities, a 'minimal' lignocellulose degrader consortium, encompassing strains so4 (identified as Citrobacter freundii on the basis of $16 \mathrm{~S}$ ribosomal RNA gene analysis) and w15 (identified as Sphingobacterium multivorum), was constructed and examined (Cortes-Tolalpa et al., 2017). The strains had been recovered from, respectively, soil- and wood-derived consortia grown on WS (Cortes-Tolalpa et al., 2016). Synergism in growth was observed exclusively in cultures with complex carbon and energy sources, i.e., WS as well as synthetic recalcitrant biomass (Cortes-Tolalpa et al., 2017), but not in cultures with glucose. Moreover, strains related to w15 and so 4 were found to be very abundant in consortia able to degrade diverse LCB substrates (Jiménez et al., 2014b; Brossi de Lima et al., 2015), suggesting their potential key roles in the degradation.

In order to establish the potential mechanisms driving the synergistic interaction between strains so4 and w15 during the WS degradation, we determined the genetic and metabolic capabilities of these two organisms, in particular with respect to their LCB degrading potential. Specifically, we evaluated the potential functional complementation between C. freundii so4 and S. multivorum w15 by analyzing their substrate utilization patterns, as well as their genome-encoded functional complements, by placing a focus on relevant LCB hydrolytic capacities.

\section{MATERIALS AND METHODS}

\section{Strains and Growth Conditions}

Strains so4 and w15, referred to as C. freundii so4 and S. multivorum w15, were isolated from microbial consortia able to degrade raw WS (Cortes-Tolalpa et al., 2016). Both strains were able to grow in monoculture using raw WS as the sole carbon and energy source (Cortes-Tolalpa et al., 2017). For routine purposes, strains were grown in TY medium $(10 \mathrm{~g} / \mathrm{L}$ tryptone; $5 \mathrm{~g} / \mathrm{L}$ yeast extract, 5 g/L NaCl; pH 7.2; Sigma-Aldrich, Darmstadt, Germany). The cultures were incubated overnight at $28^{\circ} \mathrm{C}$ and $180 \mathrm{rpm}$. Motility and temperature range of growth of each strain were determined as in Supplementary Material.

\section{BIOLOG Phenotype Testing}

BIOLOG phenotype micro arrays were used (96-well GN2 and PM2A plates; Biolog Inc., Hayward, CA, United States) to test the catabolic capabilities of $C$. freundii so4 and S. multivorum w15. The arrays consisted of totals of 190 carbon sources, encompassing alcohols, amides, amines, amino acids, carbohydrates, carboxylic acids, esters, fatty acids, and polymers. Single colonies of each strain were picked from tryptic soy agar (TSA) plates on which they were subcultured, to produce overnight cultures in TY media (with shaking at $150 \mathrm{rpm}$, at $28^{\circ} \mathrm{C}$ ). Homogeneous cell suspensions were made with IF0a GN/GP inoculation fluid (72101) and diluted to 0.001 OD at $590 \mathrm{~nm}$; in the case of the PM2A plate, the inocula were supplemented with $150 \mu \mathrm{L}$ of Biolog redox dye mix A (100X). The inocula were kept for $2 \mathrm{~h}$ at room temperature and then $150 \mu \mathrm{L}$ of the suspension was added into each well of the plates. The plates were incubated at $28^{\circ} \mathrm{C}$ and read at $0,6,12,24$, 48,72 , and $84 \mathrm{~h}$ using a microtiter plate reader at $590 \mathrm{~nm}$ (Holmes et al., 1994). Analyses of the data were performed 
using the area under the (growth) curve (AUC) as the criterion (Kalai Chelvam et al., 2015).

\section{Genomic DNA Extraction From Strains}

Total genomic DNA was extracted from the liquid and shaken TY cultures of the two strains by using the UltraClean DNA Isolation Kit (MoBio ${ }^{\circledR}$ Laboratories Inc., Carslab, United States), following the instructions of the manufacturer.

\section{Genome Sequencing and Assembly}

Whole-genome sequencing of $C$. freundii so4 and S. multivorum w15 was performed using the Illumina NextSeq 500 V2 platform by 150-bp paired-end reads (LGC Genomics Gmbh, Berlin, Germany). Assembly and scaffolding of the sequence data were performed using SPAdes 3.5.0, according to the workflow described by Nurk et al. (2013). For C. freundii so4, the final assembly resulted in 49 contigs with an N50 of 282,822 bp. For S. multivorum w15, 92 contigs were obtained, at an N50 value of $133,589 \mathrm{bp}$.

\section{Genome Annotation}

Genome drafts were annotated by the Rapid Annotation Subsystem Technology (RAST) (Aziz et al., 2008).

\section{Metabolic Pathway Comparison}

First, we determined the numbers of distinct reactions per metabolic pathway according to the enzyme commission (EC) number; EC numbers specify enzyme-catalyzed reactions and so enzymes can be diverse, for instance among different organisms. Following this first step, and taking the total number of distinct reactions per metabolic pathway as the $100 \%$ value, we calculated the percentage of distinct ECs according to the number of ECs found per strain per pathway. Finally, the functionality of the pathway was assessed by using the metabolic tool comparison in RAST. The notion of likely functioning is given by the presence of genes for all the functional roles that constitute a variant of a pathway (or subsystem) (Overbeek et al., 2014).

\section{Genome Statistics}

Predicted complete genes were translated in silico and the resulting data used to probe the Pfam database (Finn et al., 2014) as well as the COG database through the MicroScope platform (Vallenet et al., 2017). Signal-P server 4.1 was used to predict signal peptide regions (Petersen et al., 2011). Transmembrane domains were identified using THMMH server 2.0 (Krogh et al., 2001). OrthoFinder (Emms and Kelly, 2015) was used to identify single-copy genes in the genomes. PlasmidFinder was used to check the genomes for the presence of plasmids (Carattoli et al., 2014).

\section{Phylogenetic Analyses}

RNAmmer was used for identification of the rRNA genes (Lagesen et al., 2007). The 16S rRNA gene sequences (NODE_31_length_1713_cov_124.214_ID_61) of C. freundii so4 and (NODE_70_length_5327_cov_127.629_ID_139) of S. multivorum w15 were thus used for phylogenetic analyses. The 16S rRNA genes from the type strains of C. freundii and S. multivorum, as well as from closely related strains, were recovered from the SILVA ribosomal RNA database (Quast et al., 2013) and a phylogenetic tree was constructed using the Neighbor Joining (NJ) method. MEGA v 6.0 software was used to calculate pairwise P-distance values. Bootstrap analysis was performed with 1,000 repetitions.

\section{Carbohydrate-Degradative Enzymes}

Predicted genes were translated and the translates were used to search for carbohydrate-active enzymes (dbCAN); as criteria, we used coverage values above 0.5 and $e$-values $<1$ e- 18 (Yin et al., 2012; Zhang et al., 2018). Classifications of the CAZy families were done automatically by dbCAN. CAZy ${ }^{1}$ and CAZypedia ${ }^{2}$ databases were used when necessary for extra information.

\section{Genome Accession Numbers}

This whole genome sequencing project has been deposited at DDBJ/ENA/GenBank under the accession numbers PHGU00000000 and PHGV00000000. The versions described in this manuscript are PHGU01000000 and PHGV01000000. The strains used in this study have been deposited in the German Collection of Microorganisms and Cell Cultures (DMSZ, Braunschweig, Germany). C. freundii so4 is deposited under the number DSM 106340T; S. multivorum w15 is in the process of obtaining the accession number from DMSZ.

\section{RESULTS}

\section{Carbon Source Utilization Profiles C. freundii so4}

Overall, C. freundii so4 was able to grow on 52 out of the 190 carbon sources tested (Figure 1 and Supplementary Table 1), leaving a total of 138 substrates unused. The organism showed a preference for consumption of simple carbon sources, in particular eight amino acids (L-histidine, hydroxyL-proline, D-alanine, L-alanine, L-serine, D-serine, L-aspartic acid, and L-alanyl-glycine), eight carboxylic acids (succinic, 5-keto-D-gluconic, D-glucuronic, D, L-lactic, D-galacturonic, D-gluconic, D-saccharic and melibionic acid), four sugar alcohols (glycerol, D-sorbitol, D-mannitol, and $m$-inositol), two monosaccharides (D-arabinose and glucose-6-phosphate), one ketose (dihydroxyacetone) and one deoxy sugar (L-fucose) (Figure 1 and Supplementary Table 1).

\section{S. multivorum w15}

Sphingobacterium multivorum w15 could grow on only 42 out of the 190 carbon sources tested (Figure 1 and Supplementary Table 2) leaving 148 substrates unused. Interestingly, S. multivorum w15 preferred to consume complex carbon sources, such as five di-saccharides (lactulose, palatinose,

\footnotetext{
${ }^{1}$ http://www.cazy.org/

${ }^{2}$ https://www.cazypedia.org/index.php/Main_Page
} 


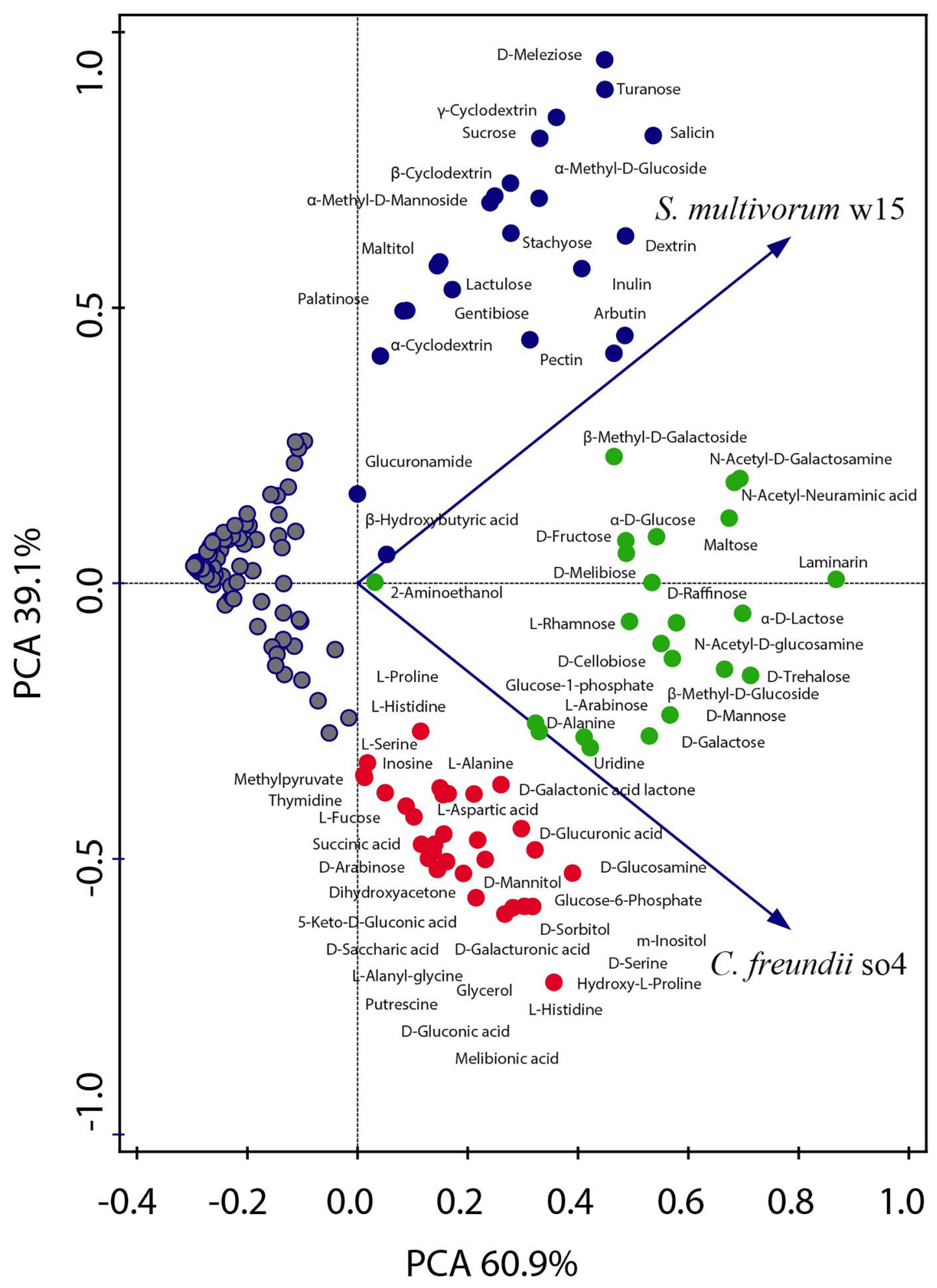

FIGURE 1 | Principal component analysis showing the metabolic capacity of the strains C. freundii so 4 and S. multivorum w15. The ability to consume each of the individual carbon sources was tested using BIOLOG PM2A and GN2 plates. C. freundii so 4 exhibited the capacity to grow on 52 compounds, mainly intermediate metabolites, amino acids, organic acids, sugar alcohols and monosaccharides (red and green). S. multivorum w15 grew on 42 compounds (blue and green), presenting preference for disaccharides, oligosaccharides and polymers. Red symbols indicate the compounds consumed only by $\mathrm{C}$. freundii so4; blue symbols those consumed only by S. multivorum w15 and green symbols those consumed by both strains. 
sucrose, turanose, and gentibiose), one trisaccharide (Dmelezitose, found in honeydew) and one tetrasaccharide (stachyose, found in legume seeds). Furthermore, it revealed an interesting capacity to grow on oligosaccharides derived from plant polymers, i.e., starch (dextrin, $\alpha$-, $\beta$ - and $\gamma$-cyclodextrins), and polysaccharides such as pectin and inulin (found in plants like chicory) (Figure 1 and Supplementary Table 2).

\section{Species-Specific and Shared Carbon Sources}

Taking the data together, 30 carbon sources were used, as the sole carbon and energy sources, by C. freundii so4, but not by $S$. multivorum w15 (Supplementary Table 1). All of these 30 carbon sources are rather simple (small) molecules, with a relatively large share of carboxylic acids $(8 ; 27 \%)$. Furthermore, strain so4 can also consume putrescine, which is produced by the breakdown of amino acids in living and dead organisms and is toxic in large doses. Conversely, 20 other compounds were used only by S. multivorum w15 (Supplementary Table 2). Most of these are more complex carbohydrates, with eight being compounds from plants, i.e., stachyose, salicin, sucrose, maltitiol, arbutin, inulin, pectin, and dextrin, suggesting a key role of strain w15 in degrading complex LCB.

Regarding shared resources, C. freundii so 4 and S. multivorum w15 were found to consume 22 compounds in similar rates. Nine of these were monosaccharides: $\alpha$-D-glucose, glucose1-phosphate, D-fructose, D-mannose, D-galactose, L-arabinose, $\beta$-methyl-D-glucose, $N$-acetyl-D-glucosamine and $\beta$-methyl-Dgalactoside. Five were disaccharides: maltose, D-melibiose, $\alpha-\mathrm{D}$ lactose, D-trehalose, and D-cellobiose. Moreover, D-alanine was the only amino acid that both strains could consume as the single carbon source, whereas the polymer laminarin was also shared between them (Figure 1 and Supplementary Table 3).

\section{Genome Descriptions}

Genomic DNA was successfully isolated and purified from both C. freundii so4 and S. multivorum w15, and subsequently fully sequenced. The genome sequencing statistics of $C$. freundii so 4 and $S$. multivorum w15 can be found in Table 1.

The genome of Citrobacter freundii so4, spread over 49 contigs, had a size of $4,883,214 \mathrm{bp}$, with an average $\mathrm{G}+\mathrm{C}$ content of $52.5 \%$. Out of the 4,703 annotated genes, 4,554 were protein-encoding genes, of which only 585 were detected as genes encoding hypothetical proteins. A total of 86 RNA-encoding genes was found. Of the latter, 11 encoded ribosomal RNA (nine $5 S$ rRNA, one 23S rRNA, and one 16S rRNA) and 75 tRNA. Only one CRISPR repeat region was found in this genome. Using plasmidfinder, no plasmids were found (Table 1).

The genome of Sphingobacterium multivorum w15, spread over 92 contigs, had a length of $6,678,278 \mathrm{bp}$, with an average $\mathrm{G}+\mathrm{C}$ content of $39.7 \%$. Of the 6,087 annotated genes, 5,999 were predicted to encode proteins, of which 734 were detected as hypothetical proteins. There were 76 genes for RNAs, of which 10 rRNAs (eight 5S rRNA, one 23S rRNA, and one 16S rRNA) and 66 tRNAs. Three CRISPR repeat sequences were found. No plasmids were found (Table $\mathbf{1}$ ).

\section{Taxonomic Affiliations}

In previous work, the (partial) PCR-amplified rRNA gene sequence of $C$. freundii so4 showed $99 \%$ similarity with that of the type strain C. freundii DSM $30039^{\mathrm{T}}$ (Cortes-Tolalpa et al., 2016), which formed the basis for its assignment to the species C. freundii. Here, we extend this analysis by aligning the full $16 \mathrm{~S}$ rRNA gene found in the genome with that of closely related strains, including the type strain. The phylogenetic tree indeed confirms strain so4 to have a very close phylogenetic relationship (>99\% match with the full sequence) with strains assigned

TABLE 1 | Genome statistics of $C$. freundii so4 and S. multivorum w15.

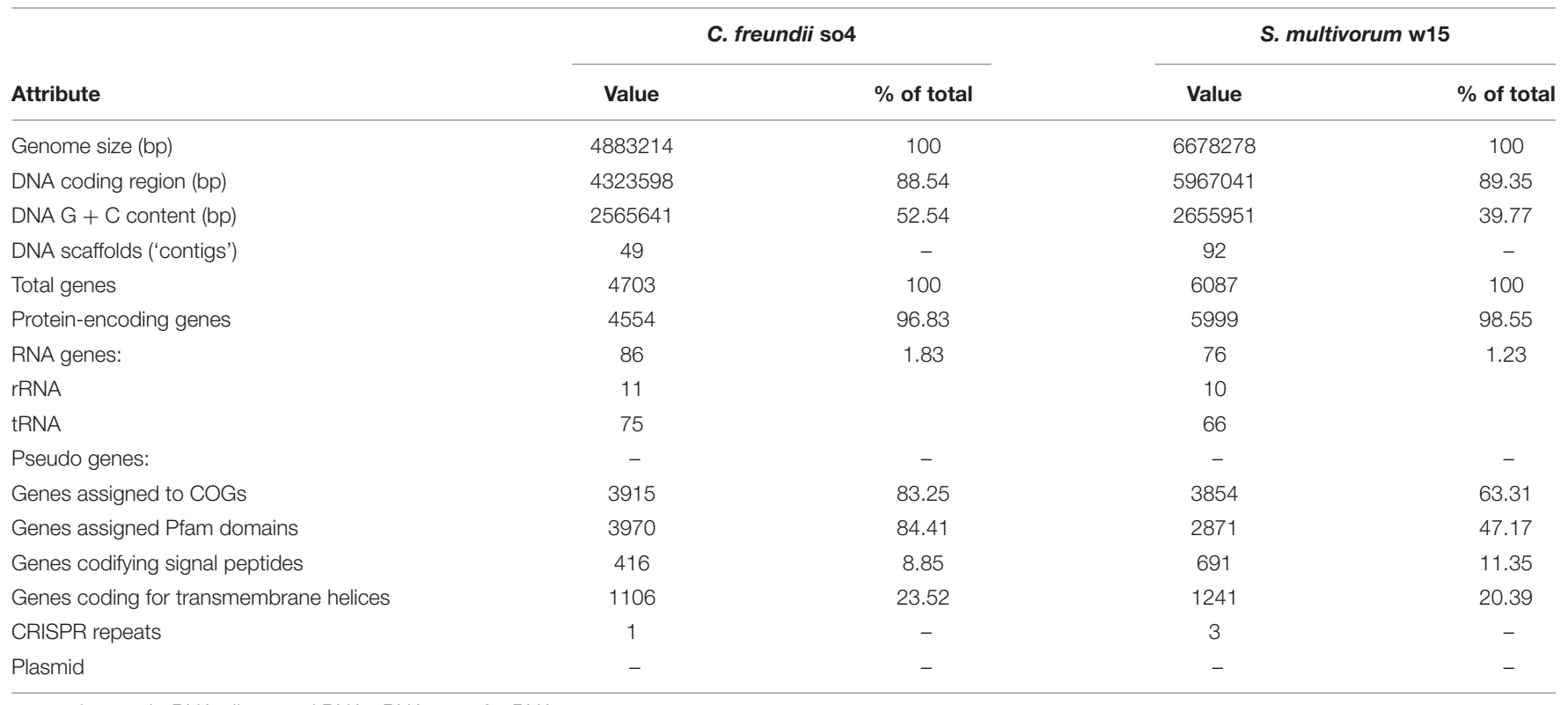

-, not detected; rRNA: ribosomal RNA, tRNA: transfer RNA. 
to Citrobacter freundii, including the type strain DSM $30039^{\mathrm{T}}$ (Supplementary Figure 1A). Consistent with this, it showed to be mesophilic, growing optimally on Lennox medium at around $30^{\circ} \mathrm{C}$ (Supplementary Figure 5A).

In a similar way, we extend the previous analysis of S. multivorum w15 based on the PCR-amplified 16S rRNA gene sequence to the full $16 \mathrm{~S}$ rRNA gene sequence from the genome. The sequence clustered into a group of sequences obtained from diverse organisms that were all classified as S. multivorum (or alike); it was $99 \%$ similar to the sequence of the type strain S. multivorum IAM $14316^{\mathrm{T}}$. In the phylogenetic tree, $S$. multivorum w15 is presented in bold (Supplementary Figure 1B). S. multivorum w15 revealed optimal growth at $28^{\circ} \mathrm{C}$, hence was also mesophilic (Supplementary Figure 5B).

\section{Assignment of Translated Genes to COG Categories}

The genome of $C$. freundii so4 was found to have 3,915 protein-encoding genes that match COG functional categories, representing $83.25 \%$ of the total and leaving $16.75 \%$ of the genes unclassified. Among the COG-recognized genes, several hundreds were found to be related with energy production and conversion (307), amino acid transport and metabolism (480) and carbohydrate transport and metabolism (413) (Table 2).

In contrast, only $63.31 \%$ of the protein-encoding genes of S. multivorum w15 (total: 3854) were associated with COG functional categories whereas the remaining $36.69 \%$ genes remained unclassified. Similar to $C$. freundii so4, hundreds of
COG-defined genes were associated with energy production and conversion (225), amino acid transport and metabolism (341) and carbohydrate transport and metabolism (355).

On the basis of the above numerical data, strain w15 did not show big differences in its allocation of genetic resources as compared to strain so4. There was one conspicuous difference: the numbers of distinct genes associated with proteins involved in 'defense' (105) and 'signal transduction' (312) in the strain w15 genome strongly exceeded those in the strain so4 genome (respectively 49 and 218), both in absolute numbers and percentages (Table 2).

\section{General Metabolism C. freundii so4}

Based on the RAST results (Supplementary Table 4), the most dominant functional category (that is, having the highest number of genes encoding proteins) in the C. freundii so4 genome was carbohydrate metabolism (706 genes, or $15.50 \%$ of the total). The second most abundant category was amino acid metabolism (438 genes), followed by cofactors/vitamins (314), protein metabolism (295), RNA metabolism (248), cell wall (236), respiration (188), membrane transport (187), stress responses (175) and lipid metabolism (166). Furthermore, C. freundii so4 revealed 143 genes associated with chemotaxis and motility (Figure 2), showing that $C$. freundii so4 can actively move in the system; this was experimentally proven, as shown in Supplementary Figure 2.

TABLE 2 | Number of genes associated with general COG functional categories.

\begin{tabular}{|c|c|c|c|c|c|}
\hline \multirow[b]{2}{*}{ Code } & \multicolumn{2}{|c|}{ C. freundii so4 } & \multicolumn{2}{|c|}{ S. multivorum w15 } & \multirow[b]{2}{*}{ Description } \\
\hline & Value & $\%$ of total ${ }^{a}$ & Value & $\%$ of total ${ }^{a}$ & \\
\hline J & 190 & 4.15 & 188 & 3.13 & Translation, ribosomal structure and biogenesis \\
\hline K & 375 & 8.20 & 460 & 7.66 & RNA processing and modification \\
\hline A & 1 & 0.02 & - & - & Transcription \\
\hline L & 174 & 3.81 & 204 & 3.40 & Replication, recombination and repair \\
\hline B & - & - & 1 & 0.02 & Chromatin structure and dynamics \\
\hline D & 47 & 1.03 & 40 & 0.66 & Cell cycle control, Cell division, chromosome partitioning \\
\hline V & 49 & 1.07 & 105 & 1.75 & Defense mechanisms \\
\hline $\mathrm{T}$ & 218 & 4.77 & 312 & 5.20 & Signal transduction mechanisms \\
\hline M & 259 & 5.67 & 333 & 5.55 & Cell wall/membrane biogenesis \\
\hline N & 130 & 2.85 & 20 & 0.33 & Cell motility \\
\hline$U$ & 123 & 2.69 & 85 & 1.42 & Intracellular trafficking and secretion \\
\hline $\mathrm{O}$ & 149 & 3.26 & 182 & 3.03 & Posttranslational modification, protein turnover, chaperones \\
\hline C & 307 & 6.72 & 225 & 3.75 & Energy production and conversion \\
\hline G & 413 & 9.04 & 355 & 5.91 & Carbohydrate transport and metabolism \\
\hline$E$ & 480 & 10.51 & 341 & 5.68 & Amino acid transport and metabolism \\
\hline $\mathrm{F}$ & 85 & 1.86 & 73 & 1.22 & Nucleotide transport and metabolism \\
\hline $\mathrm{H}$ & 165 & 3.61 & 147 & 2.45 & Coenzyme transport and metabolism \\
\hline I & 134 & 2.93 & 147 & 2.45 & Lipid transport and metabolism \\
\hline $\mathrm{P}$ & 345 & 7.55 & 425 & 7.08 & Inorganic ion transport and metabolism \\
\hline Q & 111 & 2.43 & 90 & 1.50 & Secondary metabolites biosynthesis, transport and catabolism \\
\hline $\mathrm{R}$ & 559 & 12.24 & 638 & 10.62 & General function prediction only \\
\hline S & 346 & 7.57 & 326 & 5.43 & Function unknown \\
\hline
\end{tabular}

${ }^{a}$ Based on the total number of protein-encoding genes in the genome; -, not detected. 


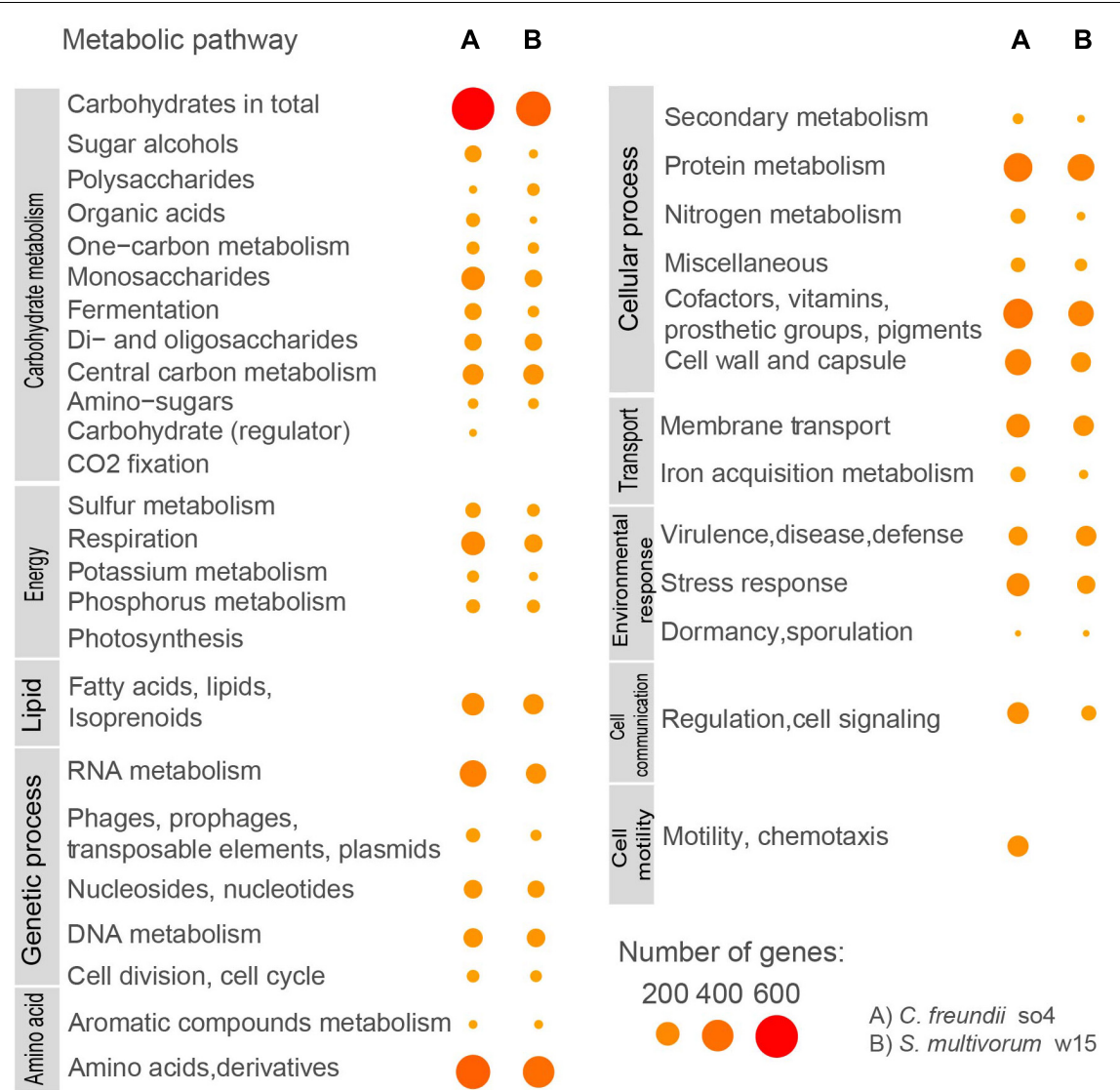

FIGURE 2 | Predicted functional subsystems in C. freundii so4 and S. multivorum w15, based on RAST results and KEGG assignments. Sizes and colors of circles indicate numbers of genes assigned to each function.

\section{S. multivorum w15}

With respect to $S$. multivorum w15, a total of 451 genes $(7.52 \%$ of the genome) was found to be associated with carbohydrate metabolism. In order of decreasing abundance, genes related with amino acid metabolism (364), protein metabolism (250), cofactors and vitamins (222), membrane transport (134), defense systems (132), lipid metabolism (132), RNA metabolism (129), cell wall (125), and DNA metabolism (104) were found. Interestingly, $S$. multivorum w15 lacked genes associated with chemotaxis and motility; tests for motility and/or chemotaxis yielded negative results (Figure 2, Supplementary Table 4, and Supplementary Figure 2).

\section{Carbohydrate Degradation}

In both C. freundii so4 and S. multivorum w15, the majority of genes encoding carbohydrate-degradative proteins was associated with the transformation of mono- next to di- and oligo-saccharides (bottom of Figure 3). In C. freundii so4, high numbers of genes were involved in monosaccharide metabolism (184), central carbon metabolism (138), di- and oligo-saccharide metabolism (86), fermentation (84), sugar alcohol metabolism (83) and 1-carbon metabolism (41) (Figure 3). In contrast, S. multivorum w15 had two- to three-fold lower numbers of genes for carbohydrate-active proteins related

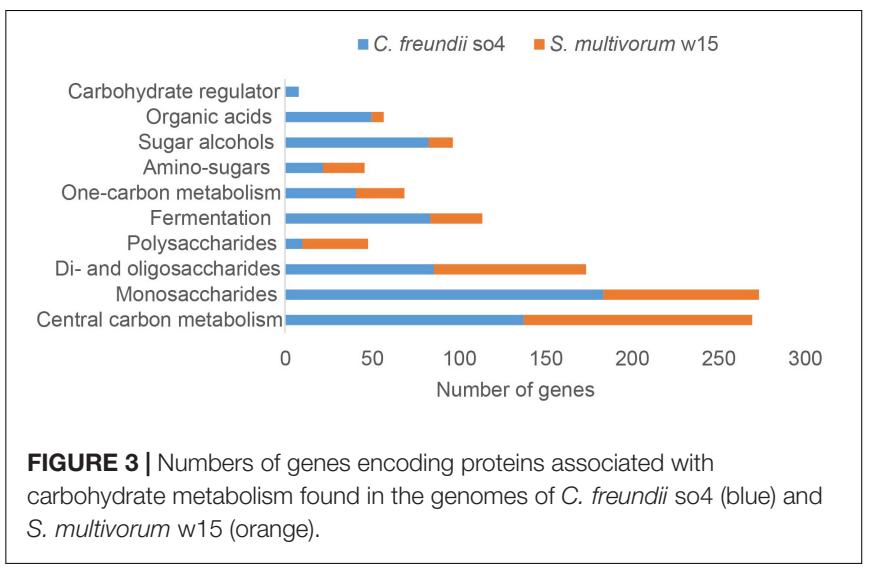

to monosaccharide, one-carbon and fermentation metabolisms. The key ones were involved in: central carbon metabolism (132) transformation/utilization of monosaccharides (90) and of di- and oligo-saccharides (88), and fermentation (30). Even though the numbers of genes for sugar alcohol and organic acid metabolisms were not the highest in C. freundii so4 (83 and 50, respectively), these numbers were still far higher than those in S. multivorum w15 (14 and 7, respectively). 
In contrast, the $S$. multivorum w15 genome contained 38 genes encoding proteins predicted to degrade polysaccharides, whereas the genome of $C$. freundii so 4 had only 10 . Here, the larger genomic complement found in S. multivorum w15 indicated that it is likely to be a vital player in the bipartite lignocellulose degradation process.

Interestingly, C. freundii so4 revealed a suite of genes (8) associated with regulation, i.e., 'carbohydrate regulation,' whereas such genes were not found in S. multivorum w15. Specifically, one gene, $\operatorname{csr} A$, was predicted to encode a carbon storage regulator. The remaining seven genes were all located in the 'carbohydrate utilization cluster' denoted Ydj, encoding: a hypothetical aldolase (YdjI), an uncharacterized sugar kinase (YdjH), a hypothetical zinc-type alcohol dehydrogenase-like protein (YdjJ), a putative oxidoreductase (YdjL), a putative transport protein $(\mathrm{YdjK})$, a hypothetical oxidoreductase (YdjG) and a putative HTH-type transcriptional regulator $(\mathrm{YdjF})$. With respect to genes for disaccharide (88) and amino sugar (24) metabolisms, S. multivorum w15 had similar gene numbers as C. freundii so4 (Figure 3).

\section{Analysis of Lignocellulolytic Potential}

The genomes of both C. freundii so4 and S. multivorum w15 showed a plethora of genes predicted to encode proteins from several CAZy families and CBMs. There were important differences between the two genomes in the total numbers of genes associated with lignocellulose degradation.

\section{GH and CBM Families}

The genome of $C$. freundii so 4 exhibited 130 genes having regions predicted to encode proteins associated with CAZy families and CBMs (Supplementary Figure 3); 125 of these 130 proteins had single (CAZy or CBM) domains, and 5 (3.85\%) had multiple domains (Supplementary Table 5). Overall, 137 domains were identified: 61 GHs, 43 glycosyl hydrolases (GTs), 18 carbohydrate esterases (CEs), 12 CBMs, 2 auxiliary activities (AAs), and 1 polysaccharide lyases (PL) (Supplementary Figure 4). Among the five multi-domain proteins, two contained a single $\mathrm{GH}$ domain associated with one CBM (CBM34-GH13, CBM48GH13), and two other ones contained a single $\mathrm{GH}$ domain associated with two (similar) CBMs (CBM48-CBM48-GH13, CBM50-CBM50-GH23). Finally, one protein contained a single GH domain and a GT domain (GT84-GH94) (Supplementary Table 6). Both the CBM48 and CBM34 modules are associated with attachment to starch; the latter was exclusively present in this strain. Specifically, out of the predicted 12 proteins with CBM domains, six were single-domain proteins, being five CBM50-like (chitin-binding) and one CBM32-like (Figure 4).

The genome of $S$. multivorum w15 exhibited 348 genes having regions predicted to encode proteins associated with CAZy families and CBMs, most of which could be directly linked with lignocellulose degradation (Supplementary Figure 3). Three hundred and thirteen out of the 348 proteins had single domains, and 35 (10.06\%) multiple domains (Supplementary Table 5). Thus, 386 domains were identified across the board: $193 \mathrm{GHs}$, 65 GTs, 56 CEs, 50 CBMs, 6 AAs, and 12 PLs (Supplementary Figure 4). Among the 35 multi-domain proteins, 23 contained a single GH domain associated with one CBM (e.g., GH16CBM16), and two contained one $\mathrm{GH}$ domain associated with two (similar) CBMs (GH29-CBM32-CBM32, GH23-CBM50CBM50). Moreover, 6 proteins contained $2 \mathrm{GH}$ domains (e.g., GH43-GH43, GH16-GH43), 1 contained 2 CBMs (CBM50CBM50), 2 two CE domains (CE7-CE15, CE3-CE6) and a final one 3 different domains (CE4-GH18-GT2) (Supplementary Table 6). Specifically, out of the 50 predicted CBM domains, 21 were identified in single-domain proteins; CBM32 (12), CBM9 (2), CBM66 (2), CBM6 (1), CBM44 (1), CBM13 (1), CBM51 (1), and CBM8 (1).

Overall, the genome of strain w15 had genes encoding proteins from 48 different $\mathrm{GH}$ families and 16 different CBM families (Figure 4), whereas the genome of strain so4 had only $25(\mathrm{GH})$ and 4 (CBM) such genes. When commonality was considered, we found that the two strains shared genes for proteins matching 36 CAZy families (Supplementary Figure 3). Conversely, regarding genes encoding proteins matching unique (CAZy and CBM) families, S. multivorum w15 had 62 unique types and C. freundii so4 20.

\section{Genes Associated With Hemicellulose Degradation}

The C. freundii so 4 genome presented genes encoding proteins matching six $\mathrm{GH}$ families related to hemicellulose degradation, i.e., GH2, GH31, GH43, GH88, GH105, and GH127. These were also present in the genome of $S$. multivorum w15 (Figure 4).

The genome of S. multivorum w15 - uniquely - exhibited putative genes encoding proteins that matched $21 \mathrm{GH}$ families involved in the degradation of hemicellulose. These were: GH2, GH10, GH16, GH28, GH29, GH30, GH31, GH43, GH51, GH53, GH67, GH76, GH78, GH88, GH92, GH105, GH106, GH115, GH116, GH120, and GH127 (Figure 4). The families with most domains identified were GH2 (19), GH29 (16), GH43 (22), and GH92 (10). Moreover, we found evidence for proteins with two different CBMs predicted to bind to xylan: CBM9 and CBM13 (all as single domain proteins). The genome also harbored genes codifying predicted proteins with CBMs capable of binding to cellulose, xylan, glucan and glucomannan, namely CBM4 (GH10CBM4), CBM6 (CBM6-GH43), CBM16 (CBM16-GH16) and CBM44 (identified in a single domain protein). Remarkably, proteins with CBM4 type domains are predicted to bind to crystalline cellulose, a very recalcitrant part of the lignocellulose substrate (Figure 4). Surprisingly, S. multivorum w15 showed evidence for the production of 22 proteins with family CBM32 domains (associated with GH29, GH43, GH31, GH2, GH20) and three of family CBM67 (associated to GH35 and GH78), as well as CBM48 (GH13-CBM48) (binding to starch), CBM50 (associated to GH23, GH73) (chitin), CBM66 (identified in a single domain protein) (fructan) and CBM61 (GH43-CBM61) (galactan) (Supplementary Table 6).

\section{Genes Associated With Cellulose Degradation}

Overall, S. multivorum w15 had more putative genes involved in cellulose degradation than C. freundii so4, as shown in Figure 4. Thus, the $C$. freundii so4 genome had only one putative gene encoding a protein from CAZy family GH5, which may be associated with the degradation of crystalline cellulose (Figure 4). 


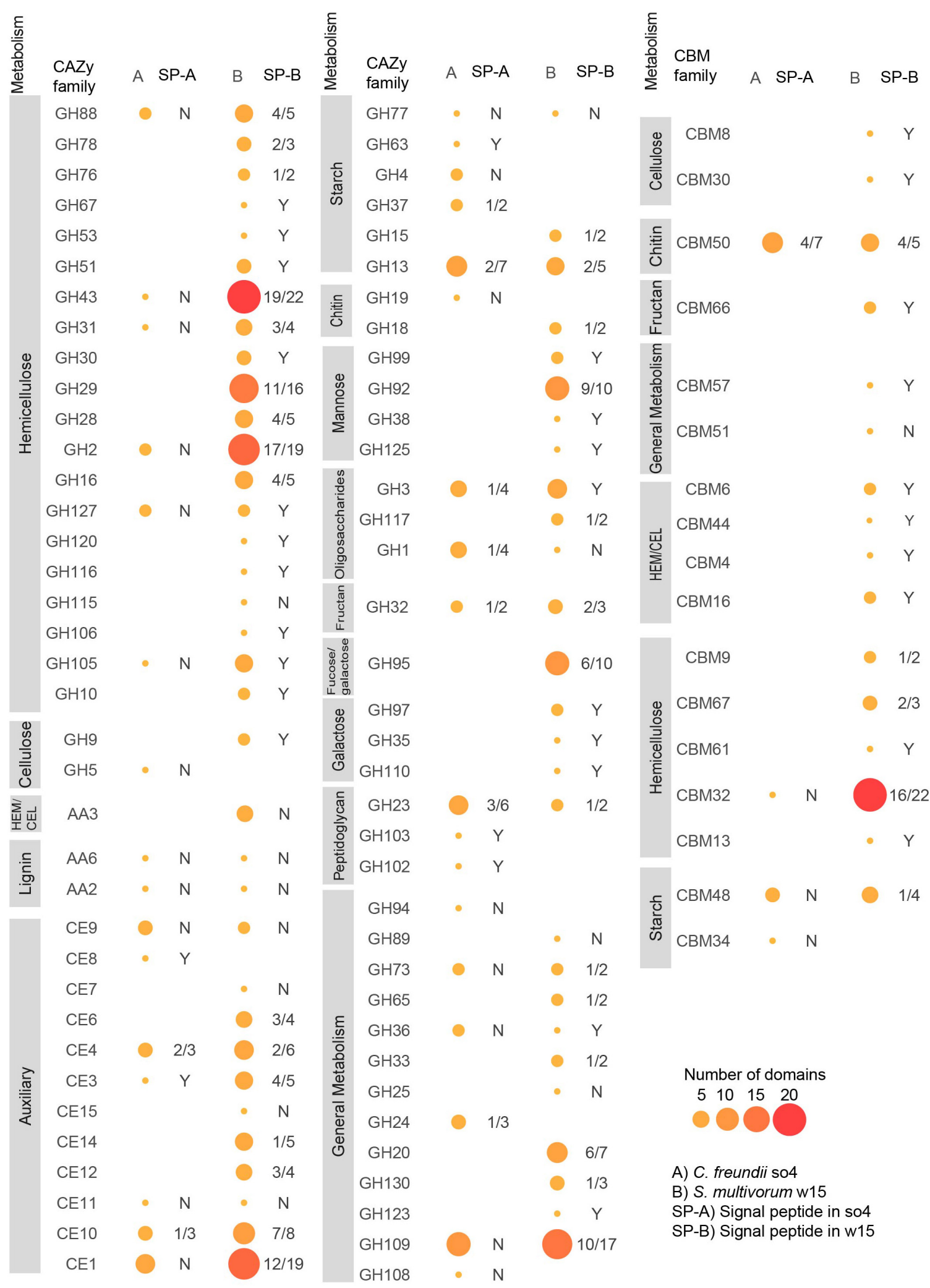

FIGURE 4 | Domain distributions in predicted proteins matching different CAZy and CBM families in C. freundii so4 (A) and S. multivorum w15 (B). Glycosyl hydrolases $(\mathrm{GH})$, carbohydrate binding modules (CBM), auxiliary activity (AA), carbohydrate esterases (CE). HEM/CEL: enzymes active on cellulose and

hemicellulose. SP-A/B is the rate of occurrence of signal peptides in the proteins found in each strain: $\mathrm{Y}=100 \%, \mathrm{~N}=0 \%, 4 / 5 \mathrm{means} 4$ out of 5 domains identified in this enzyme family have signal peptides. Sizes and colors of circles indicate the number of domains associated with each family. 
The genome of $S$. multivorum w15 uniquely presented putative genes encoding enzymes matching CAZy family GH9 (associated with cellulose degradation). Moreover, the S. multivorum w15 genome exclusively revealed the presence of predicted genes encoding proteins with domains from CBM8 and CBM30 families, which are associated with binding to cellulose.

\section{Genes for Auxiliary Enzymes}

Genes encoding enzymes of seven CE families [CE1 (6), CE3 (1), CE4 (3), CE8 (1), CE9 (3), CE10 (3) and CE11 (1)] were found in the genome of $C$. freundii so4 (Figure 4). In contrast, the genome of $S$. multivorum w15 revealed the presence of ample genes encoding enzymes of eleven CE families, including families CE1 (19), CE3 (5), CE4 (6), CE9 (2) CE10 (8), and CE11 (1). It uniquely had genes encoding proteins of the remaining five $\mathrm{CE}$ families, i.e., CE6, CE7, CE12, CE14, and CE15. Members of these protein groups have been associated with deacetylation of xylans and xylo-oligosaccharides. Also, family CE15 proteins may be responsible for breaking recalcitrant links between hemicellulose and lignin. The S. multivorum w15 genome further had four genes encoding proteins of family AA3, which includes enzymatic activities of cellobiose dehydrogenase, dehydrogenase, glucose oxidoreductases, arylalcohol oxidase, alcohol (methanol) oxidase, and pyranose oxidoreductases. These enzymes support the action of glycoside hydrolases in lignocellulose degradation and protein structural analysis indicated that such enzymes may degrade and modify cellulose, hemicellulose and even lignin (Sützl et al., 2018).

\section{Genes for Other CAZy Family Proteins}

The genome of $C$. freundii so 4 uniquely revealed genes encoding enzymes from three CAZy families associated with starch degradation, i.e., GH4, GH37, and GH63. The genome also exhibited genes for family GH13 and GH77 enzymes, which is shared with the S. multivorum w15 genome (Figure 4). S. multivorum w15 uniquely exhibited the presence of genes encoding CAZy family GH15 proteins (related to starch degradation). Moreover, it revealed a gene encoding a family GH110 protein, a polysaccharide depolymerase, which can hydrolyze galactosyl-alpha-1, 3-D-galactose linkages that are typically present in complex substrates (Figure 4).

In both genomes, we also found genes for family AA2 peroxidases, at one copy each, which are predicted to be involved in lignin degradation. Members of lytic cellulose mono oxygenases (AA10 family) were not found in any of the two genomes. Genes for CAZy family GH36 proteins were found in both genomes; the family encompasses enzymes that degrade the oligosaccharides stachyose and raffinose, present in a wide variety of plants (CAZypedia Consortium, 2017). However, C. freundii so4 only grew on raffinose as a single carbon source, whereas S. multivorum w15 could survive on both stachyose and raffinose as the single carbon source (Supplementary Tables 2, 3).

\section{CAZy and CBM Family Enzymes - Secreted or Intracellular?}

In 23 of the 130 predicted proteins matching CAZy families or CBMs of C. freundii so4, signal peptides were found (Figure 4), indicating these might be extracellular. Thus, about $18 \%$ of these proteins were secreted versus $82 \%$ potentially intracellular. Four of these were predicted to target starch, five peptidoglycan, four chitin, five 'carbohydrates' (esterases), three oligosaccharides, one fructan and one related to glycosyl transfer.

Of the 348 S. multivorum w15 predicted proteins matching CAZY families or CBMs, 202 had signal peptides (Figure 4). So, $>58 \%$ of these proteins were secreted versus $<42 \%$ intracellular. Among the former, 93 were predicted to target hemicellulose, 31 'carbohydrates' (esterases), three cellulose, 13 mannose, 6 fucose and galactose, 2 active on both hemicellulose and cellulose, 3 starch, 10 'polysaccharides' (lyases), 7 oligosaccharides, 4 fructan, 3 galactose and 3 chitin. Next to this, two had dockerins, 21 were 'general metabolism', and one a glycosyltransferase.

\section{DISCUSSION}

Citrobacter freundii so4 and S. multivorum w15 form part of a core set of bacteria that are highly abundant in LCB degrader consortia, indicating their key roles in lignocellulose degradation (Jiménez et al., 2014a; Brossi de Lima et al., 2015; Cortes-Tolalpa et al., 2016). Both strains can grow alone on WS as the sole carbon source. However, when growing together on WS, they were found to present a tight synergistic relationship (Cortes-Tolalpa et al., 2017). Clearly, knowledge of both the metabolic potential and the genomic features of the two bacteria will advance our understanding of the mechanisms behind this synergism. The data presented here show that metabolic differences and diverse polysaccharide degradation armories are potentially at the basis of the cooperation. When growing together on LCB, strain so4 and w15 may use their degrader metabolic capacities in a complementary fashion, allowing them to consume the substrates in a more efficient way than either one of them alone. Hereunder, we explore the differences found in the metabolic palettes of the two strains.

\section{Proposed Complementary Roles of C. freundii so4 and S. multivorum w15 in Wheat Straw Degradation}

Our analyses indicated that differences in catabolism between S. multivorum w15 and C. freundii so 4 growing on WS may overwhelm the competition for the same nutritional source (Figure 2 and Table 3). Overall, the genomic data and the carbon consumption profiles indicated that $C$. freundii so 4 had a metabolism that is tuned toward the transformation of simple carbon sources, such as amino acids and metabolic intermediates of glycolysis and the TCA, using these pathways for the generation of energy (Figure 1 and Table 2). Interestingly, the organism revealed enzymatic capacities for pyruvate, propanoate and ascorbate-aldarate metabolisms; the predicted proteins might be main players in (facultatively) anaerobic metabolisms (Table 3). Further predictive analyses showed that strain so4 had an active glutathione pathway (Table 3 ), which is capable of preventing damage to key cellular components caused by reactive oxygen species, such as in the detoxification of formaldehydes. Moreover, a capacity of mixed acid fermentation 
was present, which allows C. freundii so4 to grow under limited oxygen conditions (Figure $\mathbf{1}$ and Supplementary Table 1). In contrast, S. multivorum w15 (which is a strictly aerobic organism), presented a strong preference for consumption of more complex carbohydrates (Figure 1 and Supplementary Table 2). The organism probably makes use of the pentose interconversion pathway, as it appears to have considerably diminished its investment in the pyruvate, ascorbate and propionate pathways. S. multivorum w15 potentially is a prime degrader of WS polymers, making the WS more accessible to strain so4.

With respect to lignocellulose degradation, C. freundii so4 apparently prefers to consume (intermediary) sugars, products of cellulose hydrolysis and disaccharides with beta-glycosidic bonds, such as cellobiose (glucose $\beta(1 \rightarrow 4)$ glucose) and galactose ( $\beta$-D-galactosepyranosyl-D-glucopyranose) (Figure 1 and Supplementary Table 1 ). In contrast, $S$. multivorum w15 shows a propensity to utilize carbohydrates with $\alpha$ bonds such as glucose $\alpha(1 \rightarrow 4)$ glucose, melibiose ( $D$-gal- $\alpha 1 \rightarrow 6$ D-glucose) and $\gamma$-cyclodextrin (Figure 1 and Supplementary Table 2).

Another example of how the strains may complement each other with respect to their metabolism is the following. C. freundii so4 is highly versatile in its capacity to spatially explore a substrate like WS, as it, due to its flagellar apparatus, can swim to explore the locally available resources, whereas $S$. multivorum w15 cannot. This forces the latter organism to produce the plethora of extracellular enzymes that are locally required for the digestion of substrate, thus acquiring the resulting smaller molecules. It is possible that C. freundii so 4 - given its ability to move around - can readily reach those sites at the substrate where nutrients become available, taking these up in a motilityfacilitated manner.

TABLE 3 | Number of distinctive enzymes observed in different metabolic pathways found in C. freundii so4 and S. multivorum w15.

\begin{tabular}{lccc}
\hline Pathway & $\begin{array}{c}\text { Distinct } \\
\text { ECs }\end{array}$ & $\begin{array}{c}\text { C. freundii } \\
\text { so4 (\%) }\end{array}$ & $\begin{array}{c}\text { S. multivorum } \\
\text { w15 (\%) }\end{array}$ \\
\hline Citrate cycle (TCA cycle) & 41 & 63 & 59 \\
Glycolysis/Gluconeogenesis & 22 & 58 & 49 \\
Pentose phosphate pathway & 37 & 62 & 57 \\
Pyruvate metabolism & 64 & 51 & 37 \\
Propionate metabolism & 47 & 44 & 21 \\
Starch and sucrose metabolism & 71 & 30 & 30 \\
Pentose and glucuronate & 56 & 45 & 39 \\
interconversions & & & \\
Inositol phosphate metabolism & 40 & 22 & 15 \\
B-Alanine metabolism & 32 & 28 & 19 \\
Ascorbate and aldarate & 44 & 39 & 25 \\
metabolism & & & \\
Glutathione metabolism & 40 & 42 & 25 \\
\hline
\end{tabular}

Values represent the percentages of genes/enzymes needed for a functional pathway. Reference metabolic pathway highlighted (KEGG data based). Distinct reactions per metabolic pathway according to the enzyme commission (EC) number. Comparison based on KEGG database. EC numbers do not specify enzymes, but enzyme-catalyzed reactions. If different enzymes, for instance from different organisms, catalyze the same reaction, then they receive the same EC number.

\section{Model - Depiction of Roles of the Strains in the Wheat Straw Degradation System}

Cooperation based on metabolic exchange occurs when a species uses metabolites produced by another species as sources of energy or building blocks for cell structures (Cavaliere et al., 2017). The process is also known by the term cross-feeding. A key example is given by one strain degrading a primary carbon and energy source and producing a compound that is then used by a second strain (Germerodt et al., 2016). We propose that the two strains studied here, C. freundii so4 and S. multivorum w15, exhibit a cooperative cross-feeding interaction (Figure 5). While S. multivorum w15 primarily invests in the degradation of the WS hemicellulose, C. freundii so4 has other functions in the system, e.g., transforming oligo-intermediates. The consumption of the latter allows strain so4 to grow, and eventually produce secondary metabolites, that $S$. multivorum w15 can use. Also, C. freundii so4 could contribute to the detoxification of compounds in the culture (Figure 5). Three hypotheses might thus explain the positive relationship between the two strains as found on WS: (1) complementary degradation capacity, (2) production and excretion of secondary metabolites, and (3) stress response based mutualism.

\section{Complementary Degradation Capacities}

We posit here that $S$. multivorum w15 serves as the primary degrader of a complex substrate like WS, contributing with the production and release of a large variety of hydrolytic enzymes. Clearly, large parts of its genome are tuned to the degradation of xylan with different crosslinks, which is a main component of hemicellulose. As evidenced on the basis of the genome analyses, S. multivorum w15 may use mainly proteins of CAZy families GH29 and GH43. The family GH29 proteins may be exo-acting $\alpha$-fucosidases, which participate in glycan degradation (CAZypedia Consortium, 2017). In addition, the main functions reported for CAZy family GH43 enzymes are $\alpha$-L-arabinofuranosidases, endo- $\alpha$ - $\mathrm{L}$-arabinanases, $\beta$-D-xylosidases and galactosidases. A large number of enzymes in this family shows dual ( $\alpha$-L-arabinofuranosidase and $\beta$ D-xylosidase) activities, using aryl-glycosides as substrates (CAZypedia Consortium, 2017). For instance, Maruthamuthu et al. (2017) reported that a novel GH43 family enzyme had $\beta$-xylosidase $/ \alpha$-arabinosidase activities. Family GH43 enzymes are clearly implicated in the degradation of arabinoxylan, the most abundant hemicellulose component of WS (Abot et al., 2016; Mewis et al., 2016). S. multivorum w15 may also employ enzymes from CAZy family GH2, which encompasses $\beta$-galactosidases, $\beta$-glucuronidases, $\beta$-mannosidases, and exo- $\beta$-glucosaminidases. Moreover, the finding of genes for CBM32-type proteins may indicate a capacity of taking up monosaccharides and short oligosaccharides (CAZypedia Consortium, 2017). Furthermore, the finding of genes for carbohydrate esterase family 1 (CE1) proteins was revealing. Thus, S. multivorum w15 may accelerate the degradation of polysaccharides, facilitating the access of glycoside hydrolases to the substrate (Nakamura et al., 2017). CE1 is one of the largest and most diverse CE families, including acetyl xylan esterases, feruloyl esterases, and 


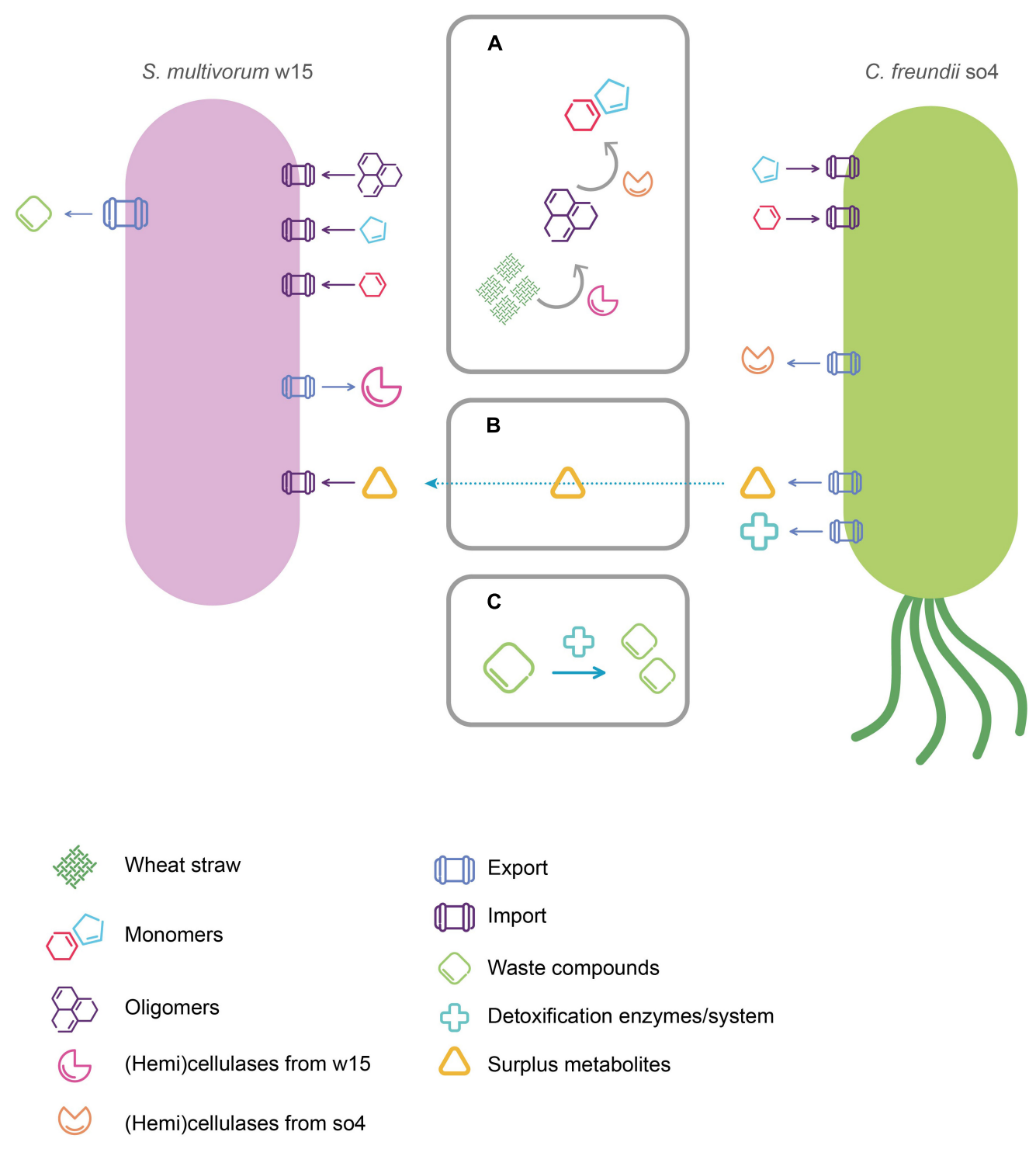

FIGURE 5 | Proposed roles of C. freundii so4 and S. multivorum w15 in the degradation of wheat straw, and mode of interaction. (A) Attack on wheat straw by (hemi)cellulases produced by C. freundii so4 and S. multivorum w15 (attacks on other compounds not depicted). (B) Potential metabolites of C. freundii so4 captured by S. multivorum w15. (C) Waste/toxic compounds removed by C. freundii so4.

carboxyl esterases that carry out the deacetylation of xylan and oligosaccharides.

On the other hand, the current evidence points to a role for C. freundii so4 as a consumer of smaller carbonaceous molecules, transforming such substrate fragments, which are produced by the action of $S$. multivorum w15, into simpler ones on the way to $\mathrm{CO}_{2}$. What then is the role of this organism as a contributor to the complex substrate degradation? C. freundii so4 may provide lytic enzymes (GH5 family) that are different from those of S. multivorum w15 (GH9 family). The most common enzymes in family GH1 are $\beta$-glucosidases and $\beta$-galactosidases, next to $\beta$-mannosidases, $\beta$ $D$-fucosidases and $\beta$-glucuronidases (CAZypedia Consortium, 2017). Furthermore, others belong to family GH13, which is the major glycoside hydrolase family acting on substrates containing $\alpha$-glucoside linkages (hydrolases, transglycosidases and isomerases - CAZypedia Consortium, 2017).

Citrobacter freundii so4 may also contribute to the WS degradation process with extracellular cellobiohydrolases that transform cellobiose into glucose monomers, which both strains can easily consume. Thus, it may hamper potential feedback inhibition processes as further discussed below. In cross feeding interactions, intermediate (by-)products of the degradation may inhibit the process (Harvey et al., 2014). An intriguing hypothesis is thus that $C$. freundii so 4 contributes to the system by processing intermediates of cellulose degradation, such as cellobiose, as degradation may be inhibited by accumulation of product. Thus, by reducing the levels of (sugar) products of S. multivorum's lytic 
activity, C. freundii so 4 may promote the activity of such enzymes in the biculture.

\section{Production and Excretion of Metabolites}

Although speculative, $C$. freundii so 4 may also contribute to the degradative system by producing and excreting metabolites that S. multivorum w15 can use, but cannot produce (for example amino acids and derivatives). Such metabolites that (temporarily) cannot be transformed, may be required to be transported out of the cell.

\section{Stress Response Modulation}

The degradation of WS by the two strains may produce potentially toxic intermediary metabolites that accumulate in the medium. These can reduce growth and enzyme production. For instance, phenolic compounds, aldehydes and furan derivatives, next to oxidative stress compounds, are known to exert this action (Malherbe and Cloete, 2002; Ling et al., 2014). Our genome analysis revealed, particularly in C. freundii so4 (but not in S. multivorum w15), the presence of:

(1) A regulon containing the oxidative stress response regulators SoxS and SoxR,

(2) Genes associated with glutathione metabolism and glutathione transcriptional regulator (formaldehyde detoxification operon - FrmR),

(3) Genes associated with nitrosative stress, specifically those for fumarate and nitrate reduction regulatory proteins,

(4) Diverse oxidoreductases that may detoxify xenobiotics, for instance, phenolics, oxidizing inorganic compounds using oxygen as the final electron acceptor (Karigar and Rao, 2011).

The finding of these genes in $C$. freundii so4 but not in S. multivorum $\mathrm{w} 15$ is consistent with the tenet that strain so 4 assists in detoxification and oxidative stress relief processes. Thus, levels of accumulated waste compounds may be reduced in the culture.

\section{CONCLUSION AND PERSPECTIVES}

The differences in the metabolic potential between $C$. freundii so4 and S. multivorum w15 make these two organisms complementary in WS degradation, as different roles for these in the system can be cogitated. Whereas $S$. multivorum w15 may have its main role in primary degradation, in particular releasing hemicellulose hydrolytic enzymes, $C$. freundii so 4 may contribute with detoxification of the system, transforming sub-products of the degradation and providing intermediate metabolites that S. multivorum w15 cannot synthesize. In this way, both strains benefit from the joint activities, yielding improved growth on a very recalcitrant carbon source.

Our study provides a starting point for an improved understanding of cooperative degrader consortia. Importantly, key target genes, e.g., those encoding proteins from CAZy families GH2, GH29, GH43, GH109, CE1, CE3, CE4, CE14, and $\mathrm{CE} 15$, as well as CBM32, were found that await further analyses. Based on these data, we suggest focusing on the expression of genes encoding proteins with CBM32 domains and enzymes from family GH43. Evidence for the importance of proteins of the latter family (Jiménez et al., 2015; López-Mondéjar et al., 2016) has been provided uniquely when strains or consortia were grow on WS, xylan and xylose.

Moreover, enzymes involved in attacks on recalcitrant regions in lignocellulose substrate need to be studied, such as members of CAZy families CE3, CE4, CE14 and CE15. Only few studies have addressed these families of enzymes in bacteria, despite the fact that many bacterial species have genes encoding them, including homologs of fungal enzymes (De Santi et al., 2016).

At the metabolic level, it is necessary to confirm the participation of $C$. freundii so4 in the system by studying the expression of metabolic pathways for the synthesis of metabolites and elimination of toxic compounds. The knowledge generated from, for instance, transcriptome analyses can be used for modulation of the system and also in the synthesis of enzyme cocktails that include hydrolytic, debranching and auxiliary enzymes for lignocellulose treatment.

\section{DATA AVAILABILITY STATEMENT}

The datasets generated for this study can be found in the DDBJ/ENA/GenBank, PHGU00000000 and PHGV00000000.

\section{AUTHOR CONTRIBUTIONS}

LC-T, JS, and JE conceived this project. LC-T and YW analyzed the CAZy data, and wrote the manuscript, with comments and revisions by JS and JE. All authors read and approved the final manuscript.

\section{FUNDING}

This work was supported by Consejo Nacional de Ciencia y Tecnología (CONACyT) through the Ph.D. scholarship to LC-T, and China Scholarship Council (CSC) though the Ph.D. scholarship to YW.

\section{ACKNOWLEDGMENTS}

We would like to thank Jolanda Brons for her technical support, Maryam Chaib de Mares for her advice for the analyses, Zhenghua Zhang, Xiu Jia, and Oksana Cortes-Tolalpa for their help with $\mathrm{R}$ program and figures, and Paul Dockerty for critical reading of this manuscript.

\section{SUPPLEMENTARY MATERIAL}

The Supplementary Material for this article can be found online at: https://www.frontiersin.org/articles/10.3389/fmicb. 2020.00248/full\#supplementary-material 


\section{REFERENCES}

Abot, A., Arnal, G., Auer, L., Lazuka, A., Labourdette, D., Lamarre, S., et al. (2016). CAZyChip: dynamic assessment of exploration of glycoside hydrolases in microbial ecosystems. BMC Genomics 17:671. doi: 10.1186/s12864-016-2988-4

Aziz, R. K., Bartels, D., Best, A. A., DeJongh, M., Disz, T., Edwards, R. A., et al. (2008). The RAST server: rapid annotations using subsystems technology. BMC Genomics 9:75. doi: 10.1186/1471-2164-9-75

Brossi de Lima, M. J., Jiménez, D. J., Cortes-Tolalpa, L., and van Elsas, J. D. (2015). Soil-derived microbial consortia enriched with different plant biomass reveal distinct players acting in lignocellulose degradation. Microb. Ecol. 71, 616-727. doi: 10.1007/s00248-015-0683-7

Carattoli, A., Zankari, E., Garcia-Fernandez, A., Volby Larsen, M., Lund, O., Villa, L., et al. (2014). PlasmidFinder and pMLST: in silico detection and typing of plasmids. Antimicrob. Agents Chemother. 58, 3895-3903. doi: 10.1128/AAC. 02412-14

Cavaliere, M., Feng, S., Soyer, O. S., and Jiménez, J. I. (2017). Cooperation in microbial communities and their biotechnological applications. Environ. Microbiol. 19, 2949-2963. doi: 10.1111/1462-2920.13767

CAZypedia Consortium (2017). Ten years of CAZypedia: a living encyclopedia of carbohydrate-active enzymes. Glycobiology 28, 3-8. doi: 10.1093/glycob/ cwx089

Cortes-Tolalpa, L., Falcao Salles, J., and van Elsas, J. D. (2017). Bacterial synergism in lignocellulose biomass degradation - complementary roles of degraders as influenced by complexity of the carbon source. Front. Microbiol. 8:1628. doi: 10.3389/fmicb.2017.01628

Cortes-Tolalpa, L., Jiménez, D. J., Brossi de Lima, M. J., Salles, J. F., and van Elsas, J. D. (2016). Different inocula produce distinctive microbial consortia with similar lignocellulose degradation capacity. Appl. Microbiol. Biotechnol. 100, 7713-7725. doi: 10.1007/s00253-016-7516-6

Cragg, S. M., Beckham, G. T., Bruce, N. C., Distel, D. L., Dupree, P., Etxabe, A. G., et al. (2015). Lignocellulose degradation mechanisms across the Tree of Life. Curr. Opin. Chem. Biol. 29, 108-119. doi: 10.1016/j.cbpa.2015.10.018

De Santi, C., Willassen, N. P., and Williamson, A. (2016). Biochemical characterization of a family 15 carbohydrate esterase from a bacterial marine arctic metagenome. PLoS One 11:e0159345. doi: 10.1371/journal.pone.0159345

Deng, Y.-J., and Wang, S. Y. (2016). Synergistic growth in bacteria depends on substrate complexity. J. Microbiol. 54, 23-30. doi: 10.1007/s12275-016-5461-9

Emms, D. M., and Kelly, S. (2015). OrthoFinder: solving fundamental biases in whole genome comparisons dramatically improves orthogroup inference accuracy. Genome Biol. 16:157. doi: 10.1186/s13059-015-0721-2

Falkowski, P. G., Fenchel, T., and Delong, E. F. (2008). The microbial engines that drive earth's biogeochemical Cycles. Science 320, 1034-1039. doi: 10.1126/ science. 1153213

Finn, R. D., Bateman, A., Clements, J., Coggill, P., Eberhardt, R. Y., Eddy, S. R., et al. (2014). Pfam: the protein families database. Nucleic Acids Res. 42, D222-D230. doi: 10.1093/nar/gkt1223

Germerodt, S., Bohl, K., Lück, A., Pande, S., Schröter, A., Kaleta, C., et al. (2016). Pervasive selection for cooperative cross- feeding in bacterial communities. PLoS Comput. Biol. 12:21. doi: 10.1371/journal.pcbi.1004986

Guerriero, G., Hausman, J.-F., Strauss, J., Ertan, H., and Siddiqui, K. S. (2016). Lignocellulosic biomass: biosynthesis, degradation, and industrial utilization. Eng. Life Sci. 16, 1-16. doi: 10.1002/elsc.201400196

Harvey, E., Heys, J., and Gedeon, T. (2014). Quantifying the effects of the division of labor in metabolic pathways. J. Theor. Biol. 360, 222-242. doi: 10.1016/j.jtbi. 2014.07.011

Himmel, M. E., Ding, S.-Y., Johnson, D. K., Adney, W. S., Nimlos, M. R., Brady, J. W., et al. (2007). Biomass recalcitrance: engineering plants and enzymes for biofuels production. Science 315, 804-807. doi: 10.1126/science.1137016

Holmes, B., Costas, M., Ganner, M., On, S. L., and Stevens, M. (1994). Evaluation of Biolog system for identification of some gram-negative bacteria of clinical importance. J. Clin. Microbiol. 32, 1970-1975. doi: 10.1128/jcm.32.8.19701975.1994

Jiménez, D. J., Chaves-Moreno, D., and van Elsas, J. D. (2015). Unveiling the metabolic potential of two soil-derived microbial consortia selected on wheat straw. Sci. Rep. 5:13845. doi: 10.1038/srep13845

Jiménez, D. J., Dini-Andreote, F., De Angelis, K. M., Singer, S. W., Salles, J. F., and van Elsas, J. D. (2017). Ecological insights into the dynamics of plant biomass-degrading microbial consortia. Trends Microbiol. 25, 788-796. doi: 10.1016/j.tim.2017.05.012

Jiménez, D. J., Dini-Andreote, F., and van Elsas, J. D. (2014a). Metataxonomic profiling and prediction of functional behaviour of wheat straw degrading microbial consortia. Biotechnol. Biofuels 7, 1-17. doi: 10.1186/1754-6834-7-92

Jiménez, D. J., Korenblum, E., and van Elsas, J. D. (2014b). Novel multispecies microbial consortia involved in lignocellulose and 5-hydroxymethylfurfural bioconversion. Appl. Biochem. Biotechnol. 98, 2789-2803. doi: 10.1007/s00253013-5253-7

Kalai Chelvam, K., Yap, K. P., Chai, L. C., and Thong, K. L. (2015). Variable responses to carbon utilization between planktonic and biofilm cells of a human carrier strain of Salmonella enterica Serovar Typhi. PLoS One 10:e0126207. doi: 10.1371/journal.pone.0126207

Karigar, C. S., and Rao, S. S. (2011). Role of microbial enzymes in the bioremediation of pollutants: a review. Access Res. Enzy. Res. 2011:805187. doi: 10.4061/2011/805187

Koeck, D. E., Pechtl, A., Zverlov, V. V., and Schwarz, W. H. (2014). Genomics of cellulolytic bacteria. Curr. Opin. Biotechnol. 29, 171-183. doi: 10.1016/j.copbio. 2014.07.002

Krogh, A., Larsson, B., von Heijne, G., and Sonnhammer, E. L. (2001). Predicting transmembrane protein topology with a hidden markov model: application to complete genomes. 11 Edited by F. Cohen. J. Mol. Biol. 305, 567-580. doi: 10.1006/jmbi.2000.4315

Kumar, S. J., Reetu, S. B., and Lakshmi Tewari, B. (2015). Lignocellulosic agriculture wastes as biomass feedstocks for second-generation bioethanol production: concepts and recent developments. Biotechnology 5, 337-353. doi: 10.1007/ s13205-014-0246-5

Lagesen, K., Hallin, P., Rødland, E. A., Stærfeldt, H.-H., Rognes, T., and Ussery, D. W. (2007). RNAmmer: consistent and rapid annotation of ribosomal RNA genes. Nucleic Acids Res. 35, 3100-3108. doi: 10.1093/nar/gkm160

Ling, H., Teo, W., Chen, B., Su Jan Leong, S., Wook Chang, M., and Wook, M. (2014). Microbial tolerance engineering toward biochemical production: from lignocellulose to products. Curr. Opin. Biotechnol. 29, 99-106. doi: 10.1016/j. copbio.2014.03.005

López-Mondéjar, R., Zühlke, D., Becher, D., Riedel, K., and Baldrian, P. (2016). Cellulose and hemicellulose decomposition by forest soil bacteria proceeds by the action of structurally variable enzymatic systems. Sci. Rep. 6:25279. doi: $10.1038 /$ srep 25279

Lynd, L. R., Weimer, P. J., van Zyl, W. H., and Pretorius, I. S. (2002). Microbial cellulose utilization: fundamentals and biotechnology. Microbiol. Mol. Biol. Rev. MMBR 66, 506-577. doi: 10.1128/mmbr.66.3.506-577.2002

Malherbe, S., and Cloete, T. E. (2002). Lignocellulose biodegradation: fundamentals and applications. Rev. Environ. Sci. Biotechnol. 1, 105-114. doi: 10.1023/a:1020858910646

Maruthamuthu, M., Jimenez, D. J., and van Elsas, J. D. (2017). Characterization of a furan aldehyde-tolerant $\beta$-xylosidase/ $\alpha$-arabinosidase obtained through a synthetic metagenomics approach. J. Appl. Microbiol. 1, 145-158. doi: 10.1111/ jam. 13484

Mewis, K., Lenfant, N., Lombard, V., and Henrissat, B. (2016). Dividing the large glycoside hydrolase family 43 into subfamilies: a motivation for detailed enzyme characterization. Appl. Environ. Microbiol. 82, 1686-1692. doi: 10.1128/AEM. 03453-15

Nakamura, A. M., Nascimento, A. S., and Polikarpov, I. (2017). Structural diversity of carbohydrate esterases. Biotechnol. Res. Innov. 1, 35-51. doi: 10.1016/j.biori. 2017.02.001

Nurk, S., Bankevich, A., Antipov, D., Gurevich, A., Korobeynikov, A., Lapidus, A., et al. (2013). Assembling Genomes and Mini-Metagenomes from Highly Chimeric Reads. Berlin: Springer.

Overbeek, R., Olson, R., Pusch, G. D., Olsen, G. J., Davis, J. J., Disz, T., et al. (2014). The SEED and the rapid annotation of microbial genomes using subsystems technology (RAST). Nucleic Acids Res. 42, D206-D214. doi: 10. 1093/nar/gkt1226

Petersen, T. N., Brunak, S., von Heijne, G., and Nielsen, H. (2011). SignalP 4.0: discriminating signal peptides from transmembrane regions. Nat. Methods 8 , 785-786. doi: 10.1038/nmeth.1701

Quast, C., Pruesse, E., Yilmaz, P., Gerken, J., Schweer, T., Yarza, P., et al. (2013). The SILVA ribosomal RNA gene database project: improved data processing and web-based tools. Nucleic Acids Res. 41, D590-D596. doi: 10.1093/nar/gks1219 
Song, H., Ding, M.-Z., Jia, X.-Q., Ma, Q., and Yuan, Y.-J. (2014). Synthetic microbial consortia: from systematic analysis to construction and applications. Chem. Soc. Rev. 43, 6954-6981. doi: 10.1039/C4CS00 $114 \mathrm{~A}$

Sorek, N., Yeats, T. H., Szemenyei, H., Youngs, H., and Somerville, C. R. (2014). The implications of lignocellulosic biomass chemical composition for the production of advanced biofuels. Bioscience 64, 192-201. doi: 10.1093/biosci/ bit037

Sützl, L., Laurent, C. V. F. P., Abrera, A. T., Schütz, G., Ludwig, R., and Haltrich, D. (2018). Multiplicity of enzymatic functions in the CAZy AA3 family. Appl. Environ. Microbiol. 102, 2477-2492. doi: 10.1007/s00253-0188784-0

Vallenet, D., Calteau, A., Cruveiller, S., Gachet, M., Lajus, A., Josso, A., et al. (2017). MicroScope in 2017: an expanding and evolving integrated resource for community expertise of microbial genomes. Nucleic Acids Res. 45, D517-D528. doi: 10.1093/nar/gkw1101

West, S. A., and Cooper, G. A. (2016). Division of labour in microorganisms: an evolutionary perspective. Nat. Rev. Microbiol. 14, 716-723. doi: 10.1038/ nrmicro.2016.111
Yin, Y., Mao, X., Yang, J., Chen, X., Mao, F., and Xu, Y. (2012). dbCAN: a web resource for automated carbohydrate-active enzyme annotation. Nucleic Acids Res. 40, W445-W451. doi: 10.1093/nar/gks479

Zhang, H., Yohe, T., Huang, L., Entwistle, S., Wu, P., Yang, Z., et al. (2018). dbCAN2: a meta server for automated carbohydrate-active enzyme annotation. Nucleic Acids Res. 46, W95-W101. doi: 10.1093/nar/gky418

Conflict of Interest: LC-T is employed by the company Agilent Technologies.

The remaining authors declare that the research was conducted in the absence of any commercial or financial relationships that could be construed as a potential conflict of interest.

Copyright (c) 2020 Cortes-Tolalpa, Wang, Salles and van Elsas. This is an open-access article distributed under the terms of the Creative Commons Attribution License (CC BY). The use, distribution or reproduction in other forums is permitted, provided the original author(s) and the copyright owner(s) are credited and that the original publication in this journal is cited, in accordance with accepted academic practice. No use, distribution or reproduction is permitted which does not comply with these terms. 